\title{
Statistical Evaluation OF MEASURED Rain ATTENUATION IN TROPICAL ClIMATE AND COMPARISON WITH PREDICTION MODELS
}

\author{
Abdulrahman A. Yusuf ${ }^{l}$, Falade, $A^{l}$, Olufeagba, B. $J^{l}$, Mohammed, O. $O^{l}$ \\ ${ }^{1}$ Electrical and Electronics Engineering Department, University of Ilorin, Nigeria \\ abdulrahman.yusuf@yahoo.com; falade.alaba@yahoo.com; lobojay12@yahoo.com; \\ reacholaabdul@gmail.com \\ Tharek A. Rahman ${ }^{2}$ \\ ${ }^{2}$ Wireless Communication Center, (WCC), Universiti Teknologi Malaysia, (UTM), Malaysia \\ tharek@fke.utm.my
}

\begin{abstract}
Substantial modifications have been made to the expressions for calculating distance factor and extrapolation techniques in the latest ITU-R P.530-14. However, its performance has not been rigorously evaluated in the tropical and equatorial climates. In this article, the new ITU-R method and three prediction models are validated using measurement data from tropical Malaysian climate. The data were collected on six geographically spread terrestrial microwave DIGI MINI-LINKs operating at 15 GHz. When tested against measurements, the Da Silva Mello model yields a significant improvement for the prediction of rain attenuation distributions. The prediction errors observed in the ITU-R model suggest the need for more data campaign in the afore-mentioned climates.
\end{abstract}

Index Terms - Distance factor, prediction models, rain-induced attenuation, RMS, tropical climates

\section{INTRODUCTION}

Traditionally frequencies above $10 \mathrm{GHz}$ are commonly employed in the current microwave point-topoint networks, due to large bandwidth and freedom from traffic congestion. However, in these frequency bands, the performance of the fixed service (FS) is predominantly controlled by rain attenuation [1]. For this reason, adequate knowledge of the propagation effects and their impact on link performance plays significant role in the design of reliable communication systems [2], [3]. The severe losses caused by rain attenuation are further aggravated due to rainfall inhomogeneity. This may become a serious problem, most especially at low percentages of time which correspond to high values of rain attenuation [4], [5].

For decades, the International Telecommunication Union-Radio Sector (ITU-R) has sought a global model for the prediction of the rain-induced attenuation on terrestrial microwave link in any climate 
of the world. The ITU-R rain attenuation prediction method yields poor results when applied to terrestrial radio links operating in the equatorial and tropical climates. This claim has been emphatically reported in a handful of published works and consequently quiet a large number of prediction models have been proposed [5, 7-11].

Some of the classical rain attenuation prediction models based on data collected on terrestrial radio Lin model [9], Moupfouma model [10], and Da Silva Mello model [11] are a few classical rain attenuation prediction models which were developed based on data collected from the equatorial and tropical climates. Recently the latest version of the ITU-R has been enforced (namely, ITU-R 530-14) in 2012; however, its performance has not been largely evaluated using data collected from tropical climates. Therefore, the main aim of this article is to evaluate the performance of the newly released ITU-R model and the three afore-mentioned models, using measurement data from six locations in a tropical climate. The data used are the rain rate and rain attenuation data banks available from six geographically spread terrestrial microwave DIGI MINI-LINKs operating at $15 \mathrm{GHz}$ as described in [13]. It should be mentioned here that the ITU-R P.530-14 was not yet in force when our previous works were reported.

\section{THEORETICAL BACKGROUND OF RAIN ATTENUATION PREDICTION MODELS}

Rain attenuation can be conveniently defined as the product of specific attenuation $(\mathrm{dB} / \mathrm{km})$ corresponding to the point rain rate (typically measured at one end of the link) and the effective propagation path length $(\mathrm{km})$ [1]. The path correction factor is defined as the ratio of effective path length to the physical path length of a microwave link, and its value is usually less than unity, except in rear cases [14].The concept of effective path length is thus a way of 'averaging out' the spatial inhomegeneity of rain rate and thus specific attenuation [15]. Note that the degree of spatial inhomogeneity in rain rate generally varies with rainfall intensity. Therefore the variation of path length reduction factor can be expressed as a function of rain rate or the corresponding time exceedance [16].

Attenuation $A_{p}$ exceeded at $\% p$ of time can either be obtained from direct measurements, or predicted from the knowledge of long-term rainfall rate. Generally, the required inputs in most attenuation prediction models for terrestrial point-to-point microwave links are the rainfall rate exceeded at $\% p$ of time, the effective propagation path length and the link's operating frequency [7], [16]. Thus $A_{p}$ exceeded at $\% p$ of time is given by:

$$
\begin{aligned}
& A_{p}\left\lfloor\gamma_{p}\left(R_{p}\right), d_{e f f}\left(R_{p}, d\right)\right\rfloor=\gamma_{p} d_{e f f} \\
& \gamma_{p}=k R_{p}^{\alpha} \\
& d_{e f f}=d r_{p}
\end{aligned}
$$


where $R_{p}(\mathrm{~mm} / \mathrm{h})$ is the rainfall rate exceeded at $\% p$ of the time, $r_{p}$ is the path correction factor at the same $\% p, d(\mathrm{~km})$ is the radio path length. Parameters $k$ and $\alpha$ depend on frequency, rain temperature, and polarization; and their values can be obtained from ITU-R P. 838-3 [17].

An overview of Lin model [7], revised Moupfouma model [8], revised Silva Mello model [9] and the newly released ITU-R model [10] is briefly presented in the following subsections.

\section{A. Lin Model}

According to Lin [7], the reduction factor can be expressed as:

$r_{p}=\frac{1}{1+L / L\left(R_{p}\right)}$

and

$L\left(R_{p}\right)=\frac{2623}{R_{p}-6.2} \mathrm{~km}$

The factor accounts for the partially correlated rain rate $R(\mathrm{~mm} / \mathrm{h})$ variations along the propagation path of length $\mathrm{L}$ such that the non linear factor in Equation (4) equals one half when $L=L(R)$ is related to the diameter of rain cell. So that the overall rain attenuation is calculated by substituting the empirical value of path reduction factor into Equation (1), as follows:

$$
A_{p}=k R_{p}^{\alpha} L\left(\frac{1}{1+L / L\left(R_{p}\right)}\right)
$$

\section{B. Revised Silva Mello's Model}

Silva Mello et al [9] identified the extrapolation procedure adopted in the older versions of the ITU-R model (ITU-R P.530-13 inclusive) as the major limitation of the prediction method. They therefore proposed the method of using the full rainfall rate distribution is introduced as input for predicting the rain attenuation cumulative distribution $(\mathrm{CD})$, and is given by [11]:

$$
A_{p}=\gamma_{R} d_{e f f}=k\left(R_{e f f}\left(R_{p}, d\right)\right)^{\alpha} \frac{1}{1+d / d_{0}\left(R_{p}\right)}
$$

where $R_{\text {eff }}$ is the effective rain rate, a function of $d$ and $R_{p}$. The expression for $R_{\text {eff }}$ and equivalent rain cell diameter $d_{0}$ are given by:

$$
R_{\text {eff }}=1.763 R^{0.753+0.197 / d}
$$

and $\quad d_{0}=119 R^{-0.244}$

The numerical coefficients in Equations (5) and (6) were obtained by multiple non-linear regressions, using the measured data currently available in the ITU-R databanks.

\section{Revised Moupfouma's Model}

According to Moupfouma [8], the equivalent propagation path length " $L_{e q}$ " is obtained by multiplying the actual relay path length " $L_{e q}$ " by an adjustment factor " $\delta$ ". Note that " $L_{T}$ " 
corresponds to the space between two ground stations, while " $\delta$ " accounts for non-uniformity of the rain on the whole propagation path.

$$
L_{e q}\left(R_{0.01} L_{T}\right)=L_{T} \exp \left(\frac{-R_{0.01}}{1+\xi\left(L_{T}\right) R_{0.01}}\right)
$$

where $\xi\left(L_{T}\right)=-100$ for any $L_{T} \leq 7 \mathrm{~km}$

and $\xi\left(L_{T}\right)=\left[\frac{44.2}{L_{T}}\right]^{0.78}$ for any $L_{T}>7 \mathrm{~km}$

Therefore, the definition of rain attenuation is modified to:

$$
A_{0.01}=k R_{0.01}^{\alpha} \cdot L_{e q}\left(R_{0.01}, L_{T}\right)
$$

where $R_{0.01}$ and $A_{0.01}$ are the rainfall rate and path attenuation at $0.01 \%$ of the time.

The model substantially overestimates the measured path attenuation, especially at lower percentages of the time.

\section{ITU-R P. 530-14 Model}

The rain attenuation exceeded at $0.01 \%$ is given by [10]:

$$
\begin{gathered}
A_{0.01}=\gamma_{R} d_{\text {eff }} \\
\gamma_{R}=k R_{0.01}^{\alpha} \\
d_{\text {eff }}=d r
\end{gathered}
$$

Substituting Equations (13) and (14) into Equation (12) yields the following

$$
A_{0.01}=k R_{0.01}^{\alpha} d\left(\frac{1}{0.477\left(d^{0.633}\right) R_{0.01}^{0.073 . \alpha} f^{0.123}-10.579[1-\exp (-0.024 d)]}\right)
$$

where $R_{0.01}(\mathrm{~mm} / \mathrm{h})$ is the rain rate exceeded at $0.01 \%$ of the time, $r$ is the path reduction factor at the same time percentage, $d(\mathrm{~km})$ is the radio path length. Parameters $k$ and $\alpha$ depend on frequency, rain temperature, and polarization, as earlier mentioned.

The attenuation $A_{p}$ exceeded for $\% p$ of the time, in the range 0.00 to $1 \%$ may be deduced from the following power law:

$$
\frac{A_{p}}{A_{0.01}}=C_{1} p^{-\left[C_{2}+C_{3} \cdot \log _{10}(p)\right]}
$$

With

$$
\left.\begin{array}{l}
C_{1}=\left(0.07^{C_{0}}\right)\left[0.12^{\left(1-C_{0}\right)}\right] \\
C_{2}=0.855 C_{0}+0.546\left(1-C_{0}\right) \\
C_{3}=0.139 C_{0}+0.043\left(1-C_{0}\right)
\end{array}\right\}
$$


where

$$
C_{0}=\left\{\begin{array}{lr}
0.12+0.4\left[\log _{10}(f / 10)^{0.8}\right] & f \geq 10 \mathrm{GHz} \\
0.12 & f<10 \mathrm{GHz}
\end{array}\right.
$$

\section{METHODOLOGY}

\section{A. Site Details}

Malaysia falls in the region $\mathrm{H}$ of the ITU-R rainfall rate climatic zoning with annual average accumulation as high as $4184.3 \mathrm{~mm}$. The Malaysian climate is tropical, and is characterized by uniform temperature, high humidity and heavy rainfall which arises mainly from the maritime exposure of the country. Thunderstorm rainfall is the most common for Malaysian climates. The monthly cumulative distribution of rainfall is influenced by seasonal monsoons, namely the northeast monsoon from October to March and the southwest monsoon from April to September [6]. The measurement sites' details are shown in Table I.

TABLE I. MEASUREMENT SITES’ DETAILS

\begin{tabular}{ccccc}
\hline Location & $\begin{array}{c}\text { Longitude } \\
\left({ }^{0} E\right)\end{array}$ & $\begin{array}{c}\text { Latitude } \\
\left({ }^{0} N\right)\end{array}$ & $\begin{array}{l}\text { Frequency } \\
(\mathrm{GHz})\end{array}$ & $\begin{array}{l}\text { Pathlength } \\
(\mathrm{km})\end{array}$ \\
\hline Penang & 100.29 & 5.27 & 14.8 & 11.3 \\
Johor Bahru & 103.43 & 1.30 & 14.8 & 5.83 \\
Alor Star & 100.25 & 6.15 & 15.3 & 4.85 \\
Kuala Lumpur & 101.36 & 3.04 & 14.8 & 3.96 \\
Taiping & 100.42 & 4.51 & 14.8 & 3.48 \\
Temerloh & 100.25 & 3.26 & 14.8 & 5.36 \\
\hline
\end{tabular}

\section{B. Experimental Procedure}

The rain attenuation data were collected from six operational point-to-point microwave links of DiGi Telecommunications Sdn. Bhd., Malaysia. Each of the microwave systems consists of a microwave MINILINK with data acquisition and processing system. The data were sampled every second and operating frequency of each of the links is $15 \mathrm{GHz}$. Both transmit and receive antennas are horizontally polarized (for example, the elevation angle is approximately zero degrees). Wet antenna effects were not included since the antennas were covered with radome during rain attenuation measurement, in order to guarantee reliable results. The positioning of the antennas were positioned in such a way that the sidelobes are not pointing to the ground. This ensures that the level of ground contamination (noise) entering the sidelobes is negligible, hence interference from any other radiating sources is negligible. Furtthermore, other effecst such as scintillations and other atmospheric absorptions along the propagation path were not considered in the study.

The automatic gain control AGC levels (volts) were converted to the corresponding receiver data in the form of equivalent power in $\mathrm{dBm}$ using the conversion chat supplied by the vendors (Sony Ericsson Mobile Communications, Kista, Stockholm, Sweden). The signal is relatively stable in the clear-sky conditions as it fluctuates within $\pm 1 \mathrm{~V}$, and the drop in AGC levels during rain represents 
path attenuation. The instability in conversion process gives fluctuations of nearly $\pm 4 \mathrm{~dB}$. From our calibration, the maximum error which may be introduced by the conversion process is $2 \%$, which means that the accuracy of rain attenuation data is $98 \%$. The dynamic range of the maximum signal strength is about $50 \mathrm{~dB}$ for excess (i.e. rain) attenuation. This is adequately suitable for covering the entire dynamic range of rain attenuation for this study, since the highest total path attenuation measured is $49.32 \mathrm{~dB}$ at $0.001 \%$ of the time. The MINI-LINKs have availability of $99.95 \%$ and their specifications are given in Table II.

TABLE II. SPECIFICATIONS OF THE $15 \mathrm{GHZ}$ LINK

\begin{tabular}{|c|c|c|}
\hline Type of antenna & \multicolumn{2}{|c|}{ Front-fed parabolic } \\
\hline Frequency band $(\mathrm{GHz})$ & \multicolumn{2}{|c|}{15} \\
\hline Polarization & \multicolumn{2}{|c|}{ Horizontal } \\
\hline $\begin{array}{l}\text { Maximum transmit power } \\
\qquad(\mathrm{dBm})\end{array}$ & \multicolumn{2}{|c|}{+18.0} \\
\hline $10^{-6} \mathrm{BER}(2 \mathrm{X} 2 \mathrm{Mbps})$ & \multirow{2}{*}{\multicolumn{2}{|c|}{-84.0}} \\
\hline Received threshold (dBm) & & \\
\hline Antenna beam width & \multicolumn{2}{|c|}{$2.3^{0}$} \\
\hline Dynamic range $(\mathrm{dB})$ & \multicolumn{2}{|c|}{$50 \mathrm{~dB}$} \\
\hline $\begin{array}{l}\text { Antenna for both } \\
\text { transmit }\end{array}$ & Size (m) & $\begin{array}{l}\text { Gain } \\
(\mathrm{dBi})\end{array}$ \\
\hline and receive side & 0.6 & 37.0 \\
\hline
\end{tabular}

The rain rate data was simultaneously recorded by positioning a Casella rain gauge, fitted with a programmable data logger, very close to the receiving antenna. The gauge is of tipping bucket type and the bucket size is $0.5 \mathrm{~mm}$ of rain. The tipping time could not be recorded, but the number of tips was recorded and stored in the built-in data logger of the rain gauge. The rain gauge's sensitivity and availability are $0.5 \mathrm{~mm} / \mathrm{min}$ and $100 \%$, respectively. It has an operating temperature range of -10 to $50^{\circ} \mathrm{C}$ and it is highly reliable with a tipping accuracy of $\pm 1.00 \%$.

The duration of rainfall measurement was four years at Kuala Lumpur and Johor Bahru. The rainfall rates were measured with one -minute integration time and the average values of the 4-year measurement were correlated with the 1-year measured attenuation data for these two locations [16]. The average of the 12-year rain rate data collected from the Malaysian Meteorological Station (MMS) were used for the remaining four sites (Penang, Taiping, Alor Star and Temerloh). The rain data have 1-h integration time, therefore Chebil and Rahman's model [18] for converting them to the equivalent 1-minute integration time. Details of the conversion procedure from 1-h to 1-minute integration can be found in [18]. The measured distributions for the rain rate and atenuation are tabulated in Tables III and IV respectively. Moreso, Figure 1 shows the rainfall distributions, while those of rain atenuation are shown in Figure 2. The equal probability plots of measured rainfall rate and rainfall attenuation for all the six sites are as shown in Figure 3, which has encompased the rainfall rate exceedance as well that of rain attenuation exceedance. 
Table III. Annual rain rate distribution

\begin{tabular}{lccccccccccc}
\hline \multirow{2}{*}{ Links } & \multicolumn{1}{c}{ Rain rate exceedance } \\
\cline { 2 - 8 } & 0.001 & 0.002 & 0.003 & 0.005 & 0.01 & 0.02 & 0.03 & 0.05 & 1.0 & 10 \\
Penang & 184 & 167 & 157 & 143 & 125 & 105 & 94 & 79 & 59 & 12 \\
Johor Bahru & 176 & 157 & 146 & 132 & 114 & 95 & 84 & 70 & 52 & 10.5 \\
Alor star & 166 & 148 & 137 & 124 & 107 & 96 & 79 & 66 & 49 & 8.9 \\
Kuala Lumpur 1 & 201 & 180 & 168 & 153 & 133 & 113 & 101 & 86 & 65 & 13 \\
Taiping & 198 & 183 & 174 & 163 & 147 & 130 & 120 & 107 & 88 & 14 \\
Temerloh & 177 & 160 & 153 & 146 & 125 & 102 & 91 & 73 & 52 & 10 \\
\hline
\end{tabular}

TABLE IV. ANNUAL RAIN ATTENUATION DISTRIBUTION

\begin{tabular}{|c|c|c|c|c|c|c|c|c|c|}
\hline \multirow[t]{2}{*}{ Site location } & \multicolumn{9}{|c|}{ Rain attenuation exceedance } \\
\hline & 0.001 & 0.002 & 0.003 & 0.005 & 0.01 & 0.02 & 0.03 & 0.05 & 1.0 \\
\hline Penang & 53.42 & 48.00 & 46.17 & 44.86 & 42.44 & 39.06 & 36.02 & 31.46 & 24.68 \\
\hline Temerloh & 40.78 & 37.59 & 36.25 & 33.14 & 29.91 & 25.77 & 23.58 & 20.35 & 14.36 \\
\hline Alorstar & 37.94 & 37.40 & 35.56 & 32.22 & 28.53 & 23.81 & 20.35 & 16.43 & 11.82 \\
\hline Kuala Lumpur 1 & 38.44 & 34.9 & 33.98 & 33.21 & 30.14 & 26.57 & 23.58 & 20 & 14.71 \\
\hline Taiping & 33.5 & 31.94 & 31.11 & 30.78 & 29.21 & 27.03 & 23.92 & 21.02 & 17.18 \\
\hline Johor Bahru & 40.78 & 37.59 & 36.25 & 33.14 & 29.21 & 25.77 & 23.58 & 20.35 & 14.36 \\
\hline
\end{tabular}




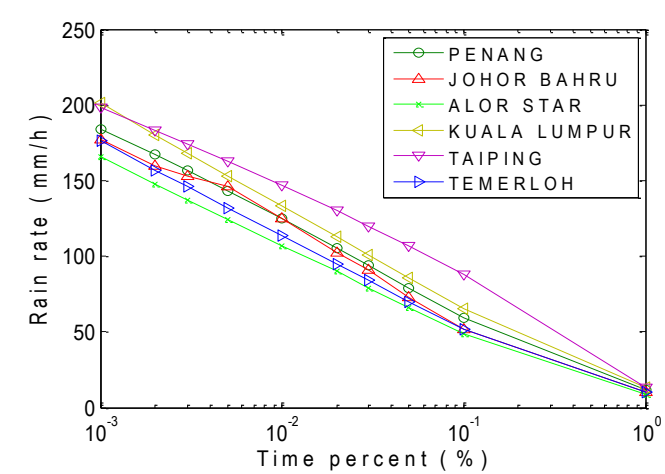

Fig. 1. Rain rate distribution

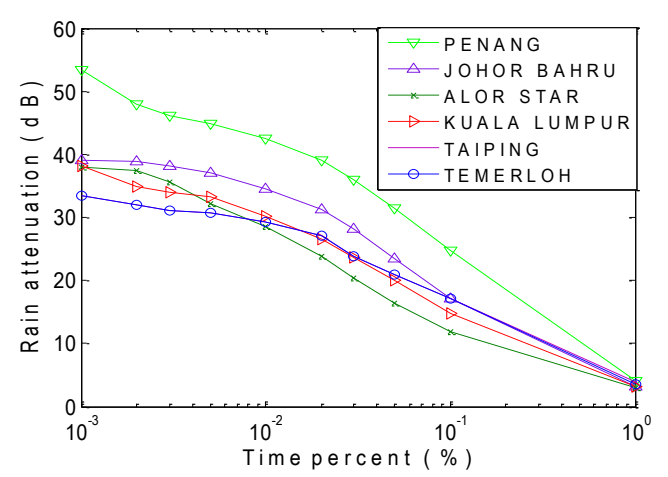

Fig. 2. Rain attenuation distribution

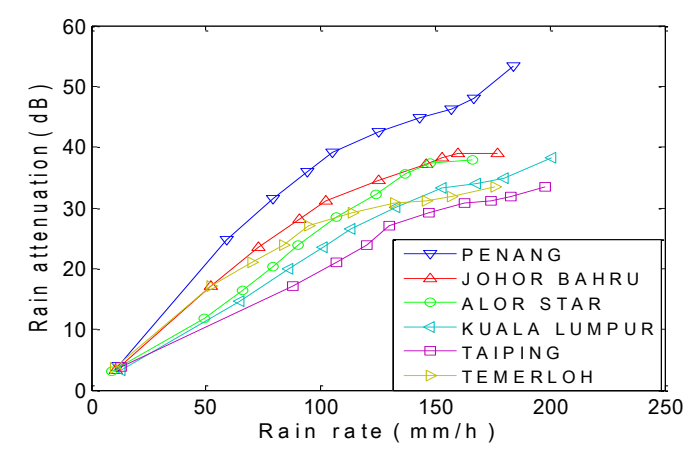

Fig 3. Equal probability plots of rain rate and rain attenuation exceedance

\section{RESULTS AND DISCUSSIONS}

The comparison of measured and predicted attenuation is shown in Figure $4(\mathrm{a}-\mathrm{f})$. In general, all the models, except Silva Mello model, overestimate measured values at high rain rates. For instance, both Lin and Moupfouma models are moderately accurate at low rain rates, in the range when $p \geq 0.05 \%$; while both largely overestimating the measured attenuation at high rain rates, when $p<0.05 \%$.

For instance, both Lin and Moupfouma models are moderately accurate at low rain rates, in the range when $p \geq 0.05 \%$; while both largely overestimating the measured attenuation at high rain rates, when $p<0.05 \%$. For the Johor Bahru link at 0.1, 0.01 and $0.001 \%$, the Moupfouma model $(22.3,59.8$ and $88.4 \mathrm{~dB})$ and Lin model $(23.1,46.9$ and $63.5 \mathrm{~dB})$ nearly coincided at $0.1 \%$ of the time, which also overestimates the measured value by almost $30 \%$. The observed overestimation in Moupfouma model overestimated measured data due to its $r \geq 1.0$ [6], [9]. This results in higher equivalent path length compared to the physical path length. That of Lin model is due overestimation of path reduction [5], [9]. 


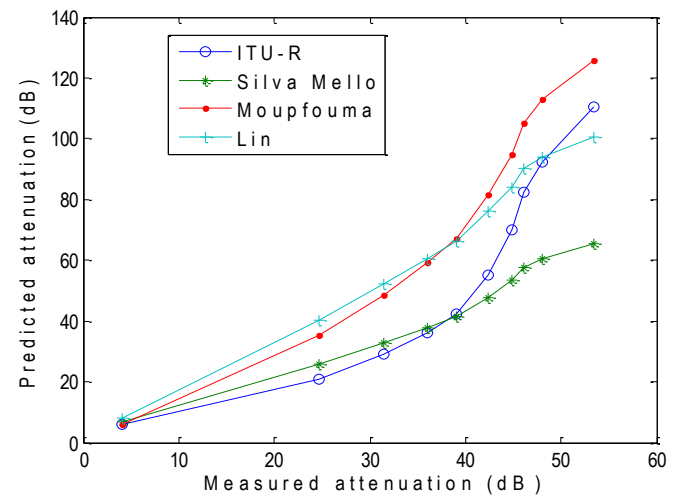

(a) Penang link

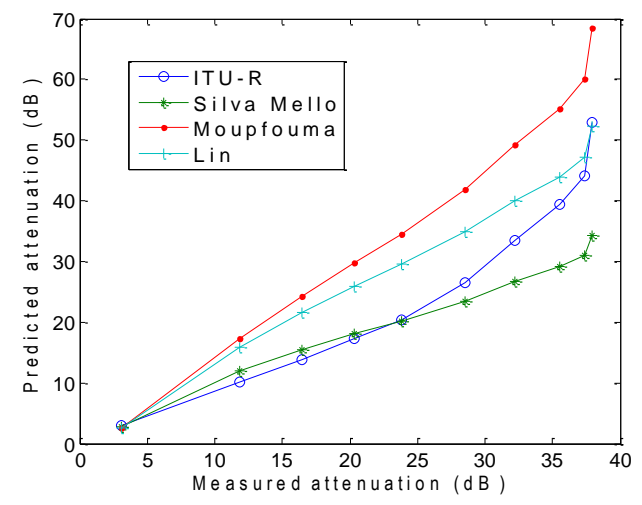

(c) Alor Star link

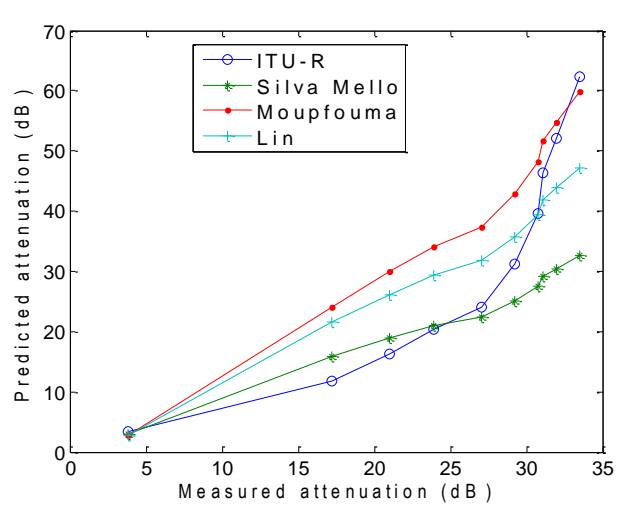

(e) Taiping link

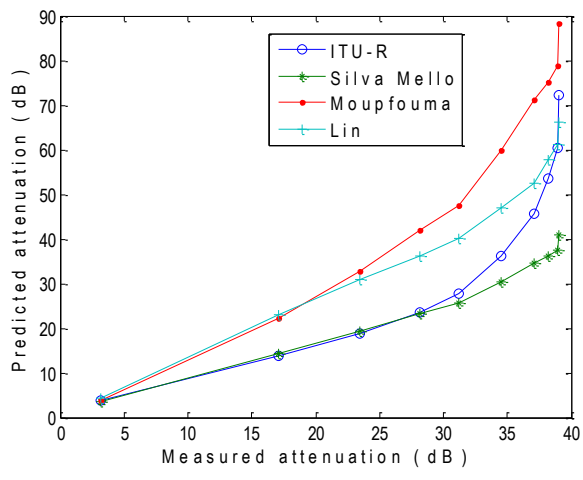

(b) Johor Bahru link

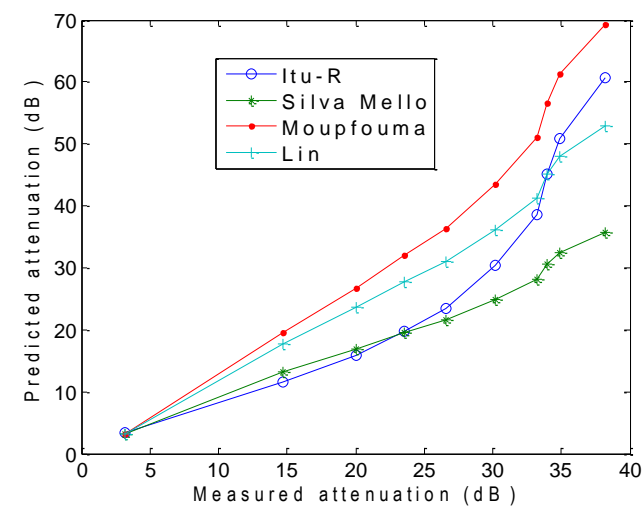

(d) Kuala Lumpur 1 link

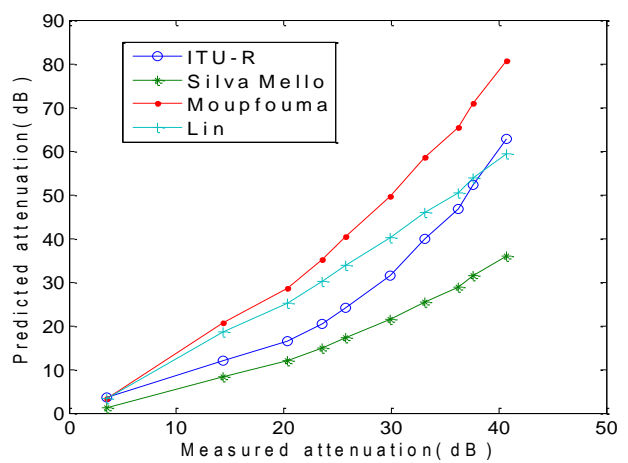

(f) Termeloh link

Fig. 4. Comparison of predicted and measured attenuation for the six links

The Silva Mello model show poor agreement with the measured data at low rain rates $((0.02 \%<p>0.1 \%))$, with percentage error between 15 and $18 \%$; worse still it largely underestimates the measurement values when rain rates are high $(p<0.01 \%)$. Satisfactory performance was observed when $p>0.01 \%$, except for the Penang link (Fig. 4a). At Penang, Mello model merely matches the measured value only when $p=0.01 \%$; while the percentage error 
lies between 4.5 and $12 \%$ for $p \neq 0.01 \%$. The ITU-R 530-14 model predicted excellently when $p=0.01 \%$. Compared to the three other models, the ITU-R model is relatively acceptable when $p<0.01 \%$; however, it largely overestimates the measurements at extremely low rain rates, when $p>0.05 \%$. Furthermore, predicted attenuation values were corelated with measured attenuation for all percentages of the time, as shown in Figure 5.

At the recommended $p=0.01 \%$ (i.e., $99.99 \%$ availability), Figure 5 presents the scatter plots of attenuation versus rain rate. The numerical values are shown in Table V. For exaample, in Figure 5, the rain rates values of $107 \mathrm{~mm} / \mathrm{h}$ and $147 \mathrm{~mm} / \mathrm{h}$ were corelated with the attenuation at $0.0 \%$ for the Alor Star and Taiping sites respectively. Similarly, the rain rate $132 \mathrm{~mm} / \mathrm{h}$ was mapped to the coresponding attenuation for Termeloh site, and so on. A special case (rain rate of $125 \mathrm{~mm} / \mathrm{h}$ ) was observed for both the Penang and Johor Bahru.

TABLE V. VALUeS OF RAIN ATtENUATION AT $0.01 \%$ OF THE TIME

\begin{tabular}{|c|c|c|c|c|c|}
\hline \multirow{2}{*}{$\begin{array}{l}\text { Location / rain } \\
\text { rate @ } 0.01 \%\end{array}$} & \multicolumn{5}{|c|}{ Attenuation at $0.01 \%$} \\
\hline & Measured & ITU-R & Silva & Moupfouma & Lin \\
\hline $\begin{array}{c}\text { Penang } \\
(125 \mathrm{~mm} / \mathrm{h})\end{array}$ & 42.44 & $\begin{array}{c}530-14 \\
55.28\end{array}$ & $\begin{array}{l}\text { Mello } \\
47.84\end{array}$ & 81.52 & 76.06 \\
\hline $\begin{array}{l}\text { Johor Bahru } \\
(125 \mathrm{~mm} / \mathrm{h})\end{array}$ & 34.5 & 36.105 & 30.39 & 59.82 & 46.85 \\
\hline $\begin{array}{c}\text { Alor Star } \\
(107 \mathrm{~mm} / \mathrm{h})\end{array}$ & 28.53 & 26.446 & 23.48 & 41.79 & 34.87 \\
\hline $\begin{array}{c}\text { Kuala } \\
\text { Lumpur } \\
(133 \mathrm{~mm} / \mathrm{h})\end{array}$ & 30.14 & 30.403 & 24.87 & 43.57 & 36.20 \\
\hline $\begin{array}{c}\text { Taiping } \\
(147 \mathrm{~mm} / \mathrm{h})\end{array}$ & 29.21 & 31.15 & 25.10 & 42.84 & 35.74 \\
\hline $\begin{array}{l}\text { Temerloh } \\
(132 \mathrm{~mm} / \mathrm{h})\end{array}$ & 29.91 & 31.34 & 21.42 & 49.59 & 40.24 \\
\hline
\end{tabular}

The significance of Figure 5 and Table $\mathrm{V}$ can be demonstrated as follows: The ITU-R specifies the availability of $99.99 \%$ (i.e, $0.01 \%$ of the time in an average year) for commercial operators. Usually propagation impairments have a significant effect only for less than one percent of the time during a year; therefore the system gain must be enhanced through an additional fade margin to meet the desired availability and quality of service, QoS specifications [3]. For example, as shown Table V, the prediction errors in the ITU-R are generally less than $2.0 \mathrm{~dB}$ except Penang link. The measured value $(42.44 \mathrm{~dB})$ was overestimated $(55.28 \mathrm{~dB})$; and the exceptional behaviour may be due to its longer path length $(11.33 \mathrm{~km})$.

Finally, the relationship between measured rain rate $R_{0.01}$ and derived path reduction $r_{0.01}$ was also investigated and plotted in Figure 6. The percentage errors of the four prediction models are 
compared in Table VI, using the Recommendation ITU-R P.311-13 [19]. When compared, Silva

Mello model shows the least mean errors $\mu_{e i}$, root mean square $D_{e i}$ and standard deviation $\sigma_{e i}$.

Table VI. PERCENTAGE ERRORS AND RMS COMPARISON

\begin{tabular}{ccccccccc}
\hline \multirow{2}{*}{$\begin{array}{c}\text { Prediction } \\
\text { models }\end{array}$} & Parameter & \multicolumn{7}{c}{ Time percentage $(\% p)$} \\
\cline { 2 - 8 } ITU-R & $\mu_{e i}$ & -0.0274 & -0.0306 & -0.0309 & -0.0276 & -0.0246 & -0.0230 & -0.0210 \\
& $\sigma_{e i}$ & 0.2475 & 0.2486 & 0.2488 & 0.2476 & 0.2475 & 0.2471 & 0.2471 \\
& $D_{e i}$ & 0.2460 & 0.2467 & 0.2469 & 0.2461 & 0.2463 & 0.2460 & 0.2462 \\
Moupfouma & $\mu_{e i}$ & 0.0434 & 0.0488 & 0.0545 & 0.0709 & 0.0851 & 0.0851 & 0.1180 \\
& $\sigma_{e i}$ & 0.7099 & 0.7096 & 0.7092 & 0.7077 & 0.7062 & 0.7050 & 0.7014 \\
& $D_{e i}$ & 0.7086 & 0.7079 & 0.7071 & 0.7042 & 0.7010 & 0.6986 & 0.6914 \\
Silva Mello & $\mu_{e i}$ & -0.0054 & -0.0098 & -0.0111 & -0.0095 & -0.0057 & -0.0031 & 0.0039 \\
& $\sigma_{e i}$ & 0.0686 & 0.0691 & 0.0693 & 0.0690 & 0.0686 & 0.0684 & 0.0685 \\
& $D_{e i}$ & 0.0688 & 0.0698 & 0.0701 & 0.0697 & 0.0688 & 0.0685 & 0.0686 \\
& $\mu_{e i}$ & 0.0382 & 0.0371 & 0.0378 & 0.0430 & 0.0495 & 0.0536 & 0.0640 \\
& $\sigma_{e i}$ & 0.4245 & 0.4246 & 0.4246 & 0.4241 & 0.4234 & 0.4229 & 0.4214 \\
& $D_{e i}$ & 0.4228 & 0.4230 & 0.4229 & 0.4219 & 0.4205 & 0.4195 & 0.4166 \\
\hline
\end{tabular}

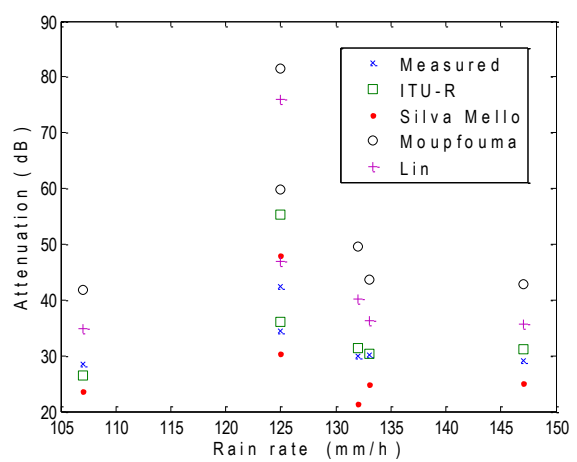

Fig. 5. Scatter plots of attenuation and rain rate $p=0.01 \%$

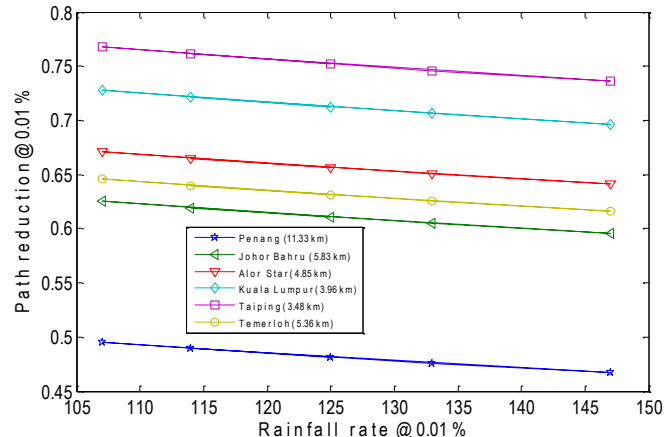

Figure 6. Relationship between experimental $r_{0.01}$ and $R_{0.01}$

\section{CONCLUSSIONS}

The newly released ITU-R P.530-14 and three classical rain attenuation prediction models are validated in this article, using the data bank available from six geographically spread DIGI MINILINKs operating at $15 \mathrm{GHz}$ in Peninsula Malaysia. Compared to the existing rain attenuation prediction models, the ITU-R model seems to provide a significant improvement upon the older ITU$\mathrm{R}$ models. For example, the new version is able to improve the much smaller value of $A_{0.01}$, compared to the one predicted by ITU-R 530-13. Also, it does not discriminate the expression for determining 
the attenuation CD regardless of the station latitude. However, the latest ITU-R model largely overestimates measurements at extremely high rain rates. This further suggests for more data campaigns from tropical and equatorial climates.

\section{ACKNOWLEDGMENT}

This research is jointly supported by Universiti Teknologi Malaysia (UTM), Malaysia and University of Ilorin, Nigeria.

\section{REFERENCES}

[1] Crane, R. K, Electromagnetic Wave Propagation Through Rain. New York: Wiley, 1996.

[2] Ojo, J. S., M. O. Ajewole, and S. K. Sarkar, "Rain rate and rain attenuation prediction for satellite communication in Ku and Ka bands over nigeria," Progress In Electromagnetics Research B, Vol.5, pp. 207-223, 2008.

[3] Abdulrahman A. Y., Rahman T. A., Rahim S. K. A. and Ul Islam M. R. A new rain attenuation conversion technique for tropical regions. Progress In Electromagnetics Research B, Vol. 26: pp. 53 - 67, 2010.

[4] Athanasios D. Panagopoulos and John D. Kanellopoulos, "Statistics of Differential Rain Attenuation on Converging Terrestrial Propagation Paths," IEEE Transactions on Antennas and Propagation, Vol. 51, No. 9, pp.2514-2517, 2003.

[5] Mandeep, JS. Rain attenuation statistics over a terrestrial link at $32.6 \mathrm{GHz}$ at Malaysia. IET Microw. Antennas Propag., Vol.3, No. 7, pp. 1086-1093, 2009.

[6] Recommendation ITU-R P.530-13: Propagation data and prediction methods required for the design of terrestrial lineof-sight systems, 2009.

[7] Pontes, M.S, Da Silva Mello L. A. R., Souza, R. S. L., Miranda, E. C. B., "Review of rain attenuation studies in tropical and equatorial regions in Brazil, In Proceeding of the $5^{\text {th }}$ International Conference on Information, Communications and Signal processing (ICICSP 05), IEEEE Xplore, Bangkok, 2005.

[8] Ojo, J. S, Ajewole, M. O., Emiliani, L. D., "One-minute rain rate countour maps for microwave communication systems planning in a tropical country: Nigeria," IEEE Antenna and Propagation Magazine, October, Vol.51, No. 5, pp. 82-89, 2009.

[9] Lin, S. H., "National long term rain statistics and empirical calculation of $11 \mathrm{GHz}$ microwave rain attenuation," The Bell System Technical Journal, vol. 56, no. 9, pp. 1581-1604, 1997.

[10] Moupfouma, F., "Electromagnetic waves attenuation due to rain: A prediction model for terrestrial or L.O.S SHF and EHF radio communication," J. Infrared Milli Terahz Waves, vol. 30, pp.622-632, 2009.

[11] Da Silva Mello, L. A. R.; Pontes, M. S.; De Souza, R. M.; Perez Garcia, N. A., "Prediction of rain attenuation in terrestrial links using full rainfall rate distribution," Electronics Letters, vol. 43, no. 25, pp.1442-1443, 2007.

[12] ITU-R, Geneva, Switzerland, "Propagation data and prediction methods required for the design of terrestrial line-ofsight systems," Recommendation ITU-R P.530-14, 2012.

[13] Abdulrahman, A. Y.; Rahman, T. A.; Abdulrahim, S. K.; Islam, M. R., "Rain attenuation measurements over terrestrial microwave links operating at 15GHz in Malaysia,” Int. J. of Com. Syst., vol. 25, pp.1479-1488, 2012.

[14] Goddard, J. W. F., Propagation in rain and cloud: Spartial temporal structure of rain, $2^{\text {nd }}$ Edition, Propagation of Radio Waves. The Institution of Electrical Engineers, IEE: U. K., 2003.

[15] Bryant GH, Adimula I, Riva C, Brussaard G. Rain attenuation statistics from rain cell diameters and heights. International Journal of Satellite Communications, Int. J. Satell. Commun., 19: pp. 263- 283, 2001.

[16] Abdulrahman, A. Y., Rahman, T. A., Abdulrahim, S. K., Islam, M. R, Abdulrahman, M. K. A. Rain Attenuation Predictions on Terrestrial Radio Links: Differential Equations Approach. Transactions on Emerging Telecommunications Technologies (TETT). vol. 23, pp.293-301, January 5, 2012.

[17] ITU-R, Geneva, Switzerland, "Specific attenuation model for rain for use in prediction methods," Recommendation ITU-R P.838-3, 2005.

[18] Chebil, J, Rahman, T. A. Rain rate statistical conversion for the prediction of rain attenuation in Malaysia. Electronics Letters, vol. 35, pp.1019-1021, 1999.

[19] ITU-R, Geneva, Switzerland, "Acquisition, presentation and analysis of data in studies of tropospheric propagation," Recommendation ITU-R P811-13, 2009. 